12th LUMEN International Scientific Conference Rethinking Social Action. Core Values in Practice | RSACVP 2019 | 15-17 May 2019 | lasi-

Romania

\title{
A Non-Parametric Efficiency Perspective on the Research-Active European Universities Performance
}

\author{
Simona GRADINARU, Anamaria ALDEA, Levida BESIR, \\ Alexandru COSER
}

https://doi.org/10.18662/lumproc.182

How to cite: Gradinaru, S., Aldea, A., Besir, L., \& Coser, A. (2019). A NonParametric Efficiency Perspective on the Research-Active European Universities Performance. In C. Ignatescu (ed.), 12th LUMEN International Scientific Conference Rethinking Social Action. Core Values in Practice, 15-17 May 2019, Iasi - Romania (pp. 371-385). Iasi, Romania: LUMEN Proceedings. https://doi.org/10.18662/lumproc.182 



\title{
A Non-Parametric Efficiency Perspective on the Research-Active European Universities Performance
}

\section{Simona GRADINARU ${ }^{1 *}$, Anamaria ALDEA ${ }^{2}$, Levida BESIR $^{3}$, Alexandru COSER ${ }^{4}$}

\author{
Abstract
}

Higher Education Institutions often struggle to optimally use their available resources in pursuance of both educational and research outputs, while competing for gathering funds. Furthermore, increasing teaching burden for academic workforce may shrink their time dedicated to research, which may also negatively impact the budget. The aim of this paper consists in examining the efficiency of two important dimensions of European universities (teaching and research), together with a possible ranking based on the models we employ for each of these two perspectives. Our target is to also explore any possible compromises between education and scientific research. We employ non-parametric efficiency analysis using FDH (Free Disposal Hull) and Hyperbolic efficiency estimators for a sample of 264 universities for the year 2014, from the RISIS-ETER facility, a database of European Higher Education Institutions and their indicators. Filters are applied to the initial heterogenous dataset in order to obtain adequate efficiency models that analyse universities performance from both research and teaching perspectives. Teaching efficiency is defined by how well the institutions manage to use their government allocation and academic staff in producing the maximum amount of undergraduate degrees, whereas the research efficiency is given by how well the universities perform in maximizing their research outputs considering only the personnel involved in research activities. The results illustrate that many institutions are focusing into a single direction and some efforts need to be undertaken in order to improve the academic

\footnotetext{
1 The Bucharest University of Economic Studies, Economic Cybernetics and Statistics Doctoral School, Bucharest, Romania, simonaegradinaru@gmail.com.

2 Department of Economic Informatics and Cybernetics, Bucharest, Romania, anamaria.aldea@csie.ase.ro.

3 The Bucharest University of Economic Studies, Economic Cybernetics and Statistics Doctoral School, Bucharest, Romania, levida.besir@gmail.com.

4 The Bucharest University of Economic Studies, Economic Cybernetics and Statistics Doctoral School, Bucharest, Romania, alexandru.coser@gmail.com.

* Corresponding author.
} 
Simona GRADINARU et al.| Lumen Proceedings 9 | RSACVP2019

balance between teaching and research. An analysis of each sample is provided and gives us an interesting insight into the European universities' activities.

Keywords: Non-parametric efficiency estimators; Free Disposal Hull (FDH) Analysis; higher education; European universities.

\section{Introduction}

Universities worldwide have known a steady but certain evolution throughout time, gaining patiently the deserved place in society. With such an amount of institutions being place nowadays, several common-sense issues may arise. How do higher education institutions perform in comparison with each other? Is there a way of improving their performance in order to achieve the expected outcomes? What is the recipe of success for an institution and what it should be focusing on? These are only few of the problems that universities encounter, for which countless plans and strategies are developed periodically.

It is no surprise that many strategies pursue efficiency across as many as possible activities. The elevated number of enrolled students have also led universities towards a need for strategies in resources allocation and management. In the context of efficiency analysis, universities are considered multi-input and multi-output decision making units. Therefore, the high level of complexity of production processes for higher education institutions is easily spotted but difficult to be captured. Educational inputs may take the shape of number of teaching academics, libraries, computer rooms, expenditures, whereas outputs may be quantified by the number of graduates or degrees, publications, number of research contracts, research income.

Another aspect worth mentioning occurs when different academic activities are rival rather than harmonizing with each other. Some would say that teaching and research are mutually exclusive, but unfortunately both use the same limited resource: time. Teaching activities do not limit only to lecturing, but include a considerable range of activities: preparing the courses, keeping the case studies up to date, training the students, review of homework and projects, guidance of theses and dissertations. When these efforts concentrate on the undergraduate students, they do not bring any contribution in expanding the research record. On the other hand, high involvement with students could be an advantage in identifying potentially researchers at an early stage in their career.

Once the teaching burden rises, the time dedicated to research heavily shrinks. New ideas take time to develop and so does researching and 
finding evidence in this purpose, from conducting the work to the final stage of writing the papers. It is extremely difficult to properly engage with a subject without dedicating large continuous blocks of time. Besides, multitasking has never turned out to be a solution, especially in the academic environment. Therefore, it is almost impossible to respect and deliver simultaneously the institutional missions outlined above. In the context of a high teaching burden, at least one of the missions will suffer from poorly accomplishment, which emphasize a possible trade-off between teaching and research that universities deal with.

This study is structured as following: the Introduction from above continues with a second section, containing a short presentation of the Problem Statement in literature. The third section summarizes the Methodology and immediately after, the fourth section gathers the findings of this study, for each model we built. The paper closes with the conclusions we underlined through this analysis.

\section{Problem Statement}

The academic environment has been and continues to be the subject of study for many non-parametric efficiency analyses in the literature. A study explores the technical and scale efficiency across both teaching and research through the use of DEA, discovering high level of efficiency in the Australian university system [1]. Other authors [3] employs two-stage DEA using bootstrapping techniques in assessing the technology transfer of French universities, revealing that a good performance is driven by the university size and its economies to scale, together with the local focus on industry and public research. The economies of scale are also the subject of study for a different paper [4], which investigates this topic for European universities through a directional based efficiency approach applied on higher education institutions and discovered that specialization does not have a significant impact on the research efficiency, whilst both size and specialisation are significant in the Humboldtian ideal combination of studies and research.

More recently, Bonaccorsi, Daraio \& Simar [2] apply directional conditional efficiency analysis on European universities and concluded that good educational efficiency (measured by graduates) does not necessarily deteriorate research efficiency, but on the other hand increasing the scientific quality may generate improvements in educational efficiency. Daraio, Bonaccorsi \& Simar [5] employ robust order-m efficiency frontiers and found some trade-offs between the quality of research and delivering 
proper teaching results in European universities, with large dissimilarities due to the national context. Using a Romanian data set, Stoica \& Aldea [11] construct order-alpha partial frontiers and also discovers some trade-offs between research activities in detriment of the time dedicated to teaching across Romanian universities, especially due to increased efforts to improve rankings in research with low funding.

\section{Research Questions/Aims of the research}

The aim of this paper consists in examining two dimensions of European universities (teaching and research), together with a possible ranking based on the models we employ for each perspective. Our target is to also explore any possible compromises between education and scientific research. We employ non-parametric efficiency analysis using Full Disposal Hull ([10]) and Hyperbolic efficiency estimators ([12]) for a sample of 271 universities for the year 2014. The data was gathered from the RISIS-ETER facility, a database of European Higher Education Institutions and their indicators.

An advantage of using non-parametric techniques is given by the lack of constraints on the variables and the models to be built. They allow us to decide which variables we want to use and how we want to build the models based on the available data and also according to the purpose we propose. In this case, we are looking into assessing the teaching and research performance of the universities and we have well documented both aspects before deciding the structure of our models.

Therefore, we define teaching efficiency by how well the institutions manage to use their government allocation and academic staff in producing the maximum amount of undergraduate degrees. On the other hand, in our perspective the research efficiency is given by how well the universities perform in maximizing their research outputs considering only the personnel involved in research activities. The results prove that many institutions are focusing into a single direction and some efforts need to be undertaken for improving the academic balance between teaching and research.

\section{Research Methods}

Efficiency and productivity analysis explore how the DecisionMaking Units (DMU) combine their inputs in order to achieve their desired outcomes. At its very beginning, efficiency started to be calculated as a ratio between outputs and inputs, similar to a yield. Later, efficiency analysis 
evolved to calculating the efficiency scores related to an efficiency frontier and linear programming turned out to be effective in this regard. Recently, the concept of efficiency has been translated into the probability theory and many approaches are still being developed. The probabilistic approach provides efficiency estimates that are fully defined and all the statistical properties are completely demonstrated. For an insight of this approach see [7], pages 19-38.

The nonparametric efficiency approach we employed in current study is the probabilistic approach of Simar and Wilson [10], whose notations we are using here too. There are two nonparametric estimators available: Data Envelopment Analysis (DEA) or Free Disposal Hull (FDH). Both of them are robust estimators, but they are extremely sensitive to outliers, which require the extreme values to be identified and eliminated prior to the analysis.

In this paper, the producing units generate a set of outputs $y \in \mathbb{R}_{+}^{q}$ by mixing a set of inputs $x \in \mathbb{R}_{+}^{p}$, as defined by Daraio and Simar [6]. The set of all possible combinations of the input-output pairs $(x, y)$ defines the production set:

$$
\psi=\left\{(\mathrm{x}, \mathrm{y}) \in \mathbb{R}_{+}^{\mathrm{p}+\mathrm{q}}, \mathrm{x} \text { can produce } \mathrm{y}\right\}
$$

Daraio and Simar [6] described the production set $\psi$ in a probabilistic approach:

$$
\psi=\left\{(\mathrm{x}, \mathrm{y}) \in \mathbb{R}_{+}^{\mathrm{p}+\mathrm{q}}, \mathrm{H}_{\mathrm{XY}}(\mathrm{x}, \mathrm{y})\right\}
$$

considering $H_{X Y}(\mathrm{x}, \mathrm{y})$ the probability of a unit $(X, Y)$ leading the production plan $(x, y)$ by producing a higher output than any $y$, under the constraint of having a smaller input than $x$.

$$
\mathrm{H}_{\mathrm{XY}}(\mathrm{x}, \mathrm{y})=\operatorname{Prob}(\mathrm{X} \leq \mathrm{x}, \mathrm{Y} \geq \mathrm{y})
$$

This probability can be decomposed as following:

$$
\mathrm{H}_{\mathrm{XY}}(\mathrm{x}, \mathrm{y})=\mathrm{H}_{\mathrm{Y} \mid \mathrm{X}}(\mathrm{y} \mid \mathrm{x}) \cdot \mathrm{F}_{\mathrm{X}}(\mathrm{x}) \text { where } \mathrm{H}_{\mathrm{Y} \mid \mathrm{X}}(\mathrm{y} \mid \mathrm{x})=\mathrm{P}(\mathrm{Y} \geq \mathrm{y} \mid \mathrm{X} \leq \mathrm{x})
$$

The efficiency frontier is given by the units using minimum input to produce maximum output:

$$
\partial \psi=\{(\mathrm{x}, \mathrm{y}) \in \Psi,(\theta \mathrm{x}, \mathrm{y}) \notin \psi, \forall 0<\theta<1 \text { and }(\mathrm{x}, \lambda \mathrm{y}) \notin \psi, \forall 0<\lambda<1\}(5)
$$

All units placed on the efficiency frontier are technically efficient, whereas the points below this boundary are technically inefficient.

When measuring the efficiency of a unit $(x, y)$, Deprins et al [7] suggested to determine it relative to the free-disposal hull (FDH) and so it appeared the FDH estimator of $\psi$ :

$$
\widehat{\Psi}_{\mathrm{FDH}}\left(\chi_{\mathrm{n}}\right)=\left\{(\mathrm{x}, \mathrm{y}) \in \mathbb{R}_{+}^{\mathrm{p}+\mathrm{q}} \text {, where } \mathrm{y} \leq \mathrm{y}_{\mathrm{i}}, \mathrm{x} \geq \mathrm{x}_{\mathrm{i}},\left(\mathrm{x}_{\mathrm{i}}, \mathrm{y}_{\mathrm{i}}\right) \in \chi_{\mathrm{n}}\right\}
$$

In this setup, the output-oriented FDH measure of efficiency score of a higher education institution is given by:

$$
\hat{\lambda}_{\mathrm{FDH}}=\max \left\{\lambda \mid(\mathrm{x}, \lambda \mathrm{y}) \in \widehat{\Psi}_{\mathrm{FDH}}\right\}
$$


Färe and Grosskopf [8] introduced a hyperbolic measure of technical efficiency with the purpose of removing the input or output orientation and using a more general approach. The hyperbolic measure of technical efficiency pursues any possible pairs by diminishing the input with $\gamma$, simultaneously with increasing the output with $\gamma^{-1}$, which was later defined by Wilson [12] as following:

$$
\gamma(\mathrm{x}, \mathrm{y})=\inf \left\{\gamma>0 \mid\left(\gamma \mathrm{x}, \gamma^{-1} \mathrm{y}\right) \in \psi\right\}
$$

In the probabilistic approach, the above efficiency estimate becomes:

$$
\gamma(\mathrm{x}, \mathrm{y})=\inf \left\{\gamma>0 \mid H_{Y \mid X}\left(\gamma \mathrm{x}, \gamma^{-1} \mathrm{y}\right)>0\right\}
$$

The hyperbolic efficiency estimates allow adjusting the inputs and the outputs simultaneously and without a specific orientation. Insights of this approach and its according statistical properties are proven in Wilson [12].

The hyperbolic approach provides a base that allow us to obtain a ranking on DMU. Another approach that doesn't take account the orientation in the input-output space is a directional distance function approach (Daraio and Simar [6]).

\section{Findings}

The previous techniques were applied on the data provided by RISIS-ETER facility, a database containing various descriptors on European Higher Education Institutions (HEI), gathering evidence on 2764 universities from 12 European countries according to year 2014. Unfortunately, a high amount of the dataset contained only partial information, leading to keep into analysis only 271 different institutions, out of which we selected 264 universities. Table 1 illustrates the 7 variables we selected to describe universities performance.

Table 1. Descriptive variables for universities.

\begin{tabular}{lll}
\hline Category & Variable & Description \\
\hline Teaching & ACSTAF & Academic personnel (headcount) \\
& GOVAL & Basic government allocation \\
& GRAD & Number of graduates at ISCED 5-7 \\
\hline Research & PROF & Number of full professors (headcount) \\
& PHDSTUD & Students enrolled at ISCED 8 \\
& PUB & Count of publications of the Web of
\end{tabular}


Simona GRADINARU et al.| Lumen Proceedings 9 | RSACVP2019

Science document (articles, reviews)

CIT Average number of citations of publications

EUFP Number of EU-FP participations (covers

FP5, FP6 and FP7)

Before beginning any efficiency analysis, a clear examination of the dataset needed to be conducted. Variables have different measurement scales, some variables with large ranges. Since heterogeneity may have an influence on the efficiency frontier, a detailed analysis is needed. Table 2 gives summary statistics, proving again some heterogeneity through large data ranges.

The highest academic staff is reached by KU Leuven, a university with a prolonged tradition of pioneering research and high-quality education. Federal Institute of Technology Zürich (ETHZ) records the largest government allocation, receiving strong support from the Swiss Government. The peak of ISCED 5-7 graduates in the data set is registered by Sapienza University of Rome, as an acknowledgement of its strong history and background. With regards to both number of full professors and participations to Framework Programs, University of Oxford has an outstanding performance comparing to the other institutions included, which is not surprisingly considering the numerous research activities led and their awards and recognitions. Highest number of $\mathrm{PhD}$ students is gathered by University College London, an institution committed to research as part of its mission which attracts many passionate students in this regard.

Table 2. Descriptive statistics of variables.

\begin{tabular}{llrrrr}
\hline Category & Variable & Mean & St. dev. & Min & Max \\
\hline Teaching & ACSTAF & 1551 & 1438.208 & 76 & 9069 \\
& GOVAL & 102.575 & 130.855 & 0.140 & 1010.720 \\
& GRAD & 4633 & 3341.207 & 117 & 21973 \\
\hline Research & PROF & 132.500 & 182.820 & 10 & 1160 \\
& PHDSTUD & 509.500 & 1010.480 & 10 & 5870 \\
& PUB & 477.703 & 615.626 & 2 & 3380 \\
& CIT & 4.781 & 1.833 & 0.622 & 13.835 \\
& EUFP & 43.070 & 65.270 & 1 & 389 \\
\hline
\end{tabular}


In order to assess the teaching and research performance of universities, we combined the variables into two models. Teaching efficiency is defined by how well the institutions manage to use their government allocation and academic staff in producing the maximum amount of undergraduate degrees. With this in mind, we built a teaching model with two inputs: academic personnel and government funds, and a single output, graduates at ISCED 5-7.

On the other hand, we thought the research efficiency to be given by how well the universities perform in maximizing their research outputs considering only the personnel involved in research activities. But based on the research amplitude, some institutions may focus on writing more publications or participating to research programs, while others may concentrate their efforts in improving the quality of their publications given by citation score, since they may be publishing constantly numerous publications. This judgement led us two built two different research models, with universities differentiated by the number of publications. First model, also referred as research model 1, takes into account the universities with a lower amount of publications and uses three inputs given by the academics involved in research activities: academic staff, professors and $\mathrm{PhD}$ students and two outputs: publications and EU-FP participations. Research model 2 uses the same inputs as the previous model and a single output, citation score.

Before running the analysis, the initial heterogenous dataset was filtered by the number of publications in order to obtain adequate efficiency models that analyse universities performance. This led to splitting the dataset in two, one half containing 179 institutions and the other one with 85, based on the number of publications, which influence the research dimension. Therefore, we built the research models in this configuration. We also make the difference between the outputs targeted for each group: while lower publications universities aim for expand their publications and EU-FP participations, higher publications institutions no longer have this issue, their focus being switched towards improving their citation score. 


\subsection{Nonparametric efficiency analysis: Research}

A principal components analysis ran on the subset with lower publications institutions revealed the inputs and outputs being clear separated. In the pursue of a homogenous data set for the nonparametric efficiency analysis, we have also tried to run a cluster analysis, but the solutions were weak and not very well delimited. In this context, we decided to continue working on those 184 universities.

\section{Research Model}

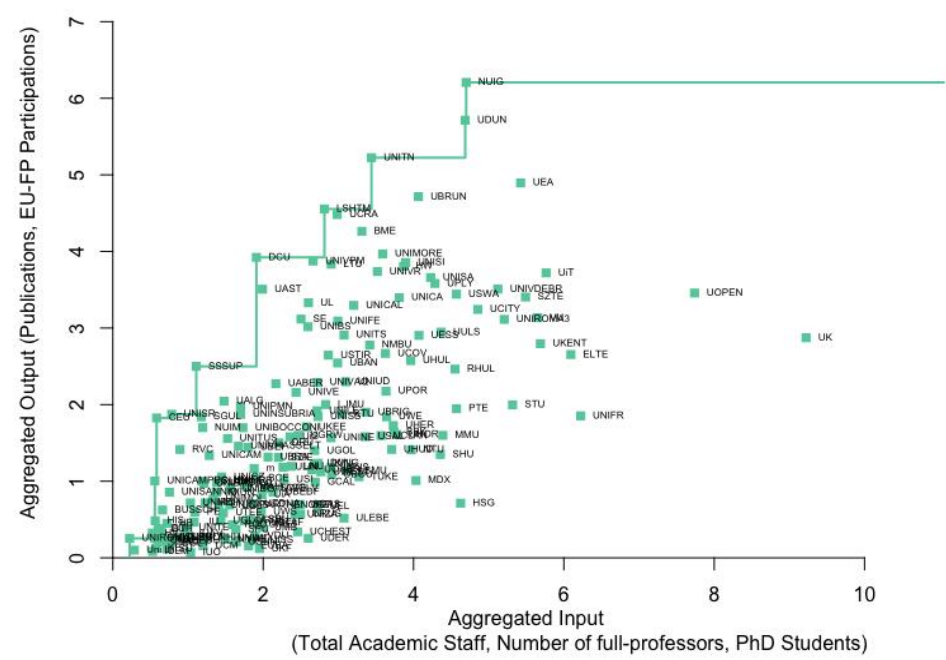

Figure 1. Efficiency frontier (FDH) for the research model 1 (lower publications universities).

In order to obtain the production frontier, a bi-dimensional data set is required, one dimension containing the input and the other one with output. Consequently, an aggregation of both inputs and outputs was required for a proper graphical representation of the production frontier. We employed the method proposed by Mouchart and Simar [9], used for avoiding the issue of small data sets, known as the curse of dimensionality, that affects the efficiency estimators. In order to avoid the curse of dimensionality, we can employ order-alpha efficiency estimators or bootstrap, using the approach of Daraio and Simar [6]. The approach constructs the aggregated variables as a linear combination of the standardized variables (dividing them by their according standard deviation), whether they are inputs or outputs. Our aggregated input and output proved to be highly correlated (correlations overcoming 0.85 ) with the initial variables used in aggregation. 
The average FDH efficiency estimate for this model reaches a value of 0.695 , which split the data set into 87 inefficient (47.3\% of sample) and 97 efficient universities $(52.7 \%$ of sample), with group averages efficiency estimates of 0.420 and 0.942 , respectively. The results are visually illustrated in Figure 2. Although the efficient universities have on average smaller inputs, they manage to produce not only higher outcomes, but actually double outputs in the context of research.

The remaining part of the data set was similarly examined. An initial principal components analysis was run, revealing that inputs and outputs are clear separated and properly tied with each other. Analogous, several solutions of cluster analysis were examined, but their quality was extremely weak and vague delimited, leading us to believe that it is better to use those 87 universities without applying any other dimensional reduction techniques, except for the aggregation of inputs. Similarly, the correlations between the aggregated input and the initial variables composing it are higher than 0.85 , proving a high correlation between them and a low lack of information through this transformation.

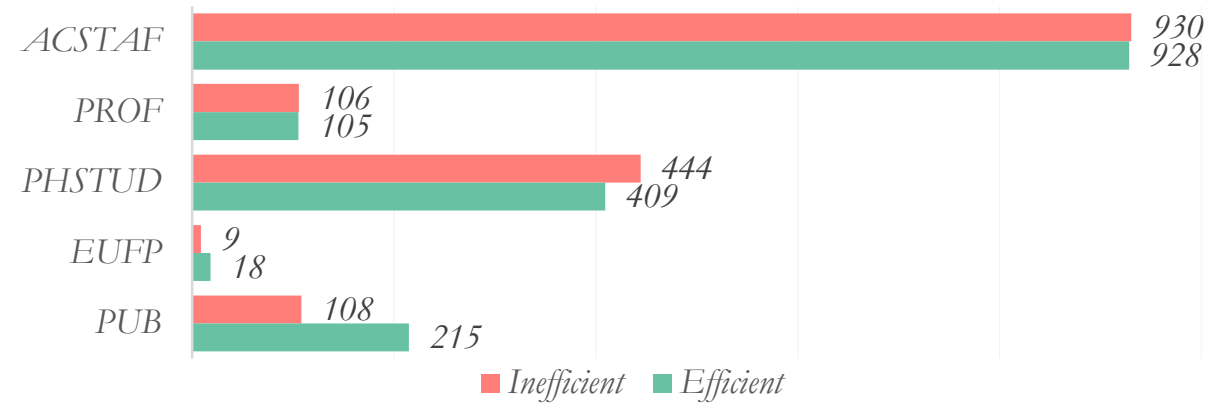

Figure 2. Comparison between efficient and inefficient universities, according to the research model 1 (lower publications).

A second research model was run on the remaining 87 universities with publications above average, with the same configuration of inputs and a different output: mean citation score. This time, the FDH efficiency estimate went up to an average of 0.792 , splitting the universities in 43 inefficient (49.4\% of sample) and 44 efficient HEIs (50.6\% of sample). The average FDH efficiency estimates reach 0.653 for the inefficient group and 0.928 for the efficient one. Figure 3 illustrates the production frontier for the research model 2, built using an aggregated input of 3 variables and a single output. The graph easily spots EPFL (Federal Institute of Technology Lausanne) as an extreme value, which we decided to keep it into the analysis because we wanted to study its performance in comparison to the other universities, 
since we have noticed that this institution has the largest citation score among these 87 universities, although its publication are not in the upper third quartile.

In comparison to the previous category of institutions, this group of universities scored a higher average FDH efficiency estimate, confirming that HEIs with a superior amount of publications have academic personnel and $\mathrm{PhD}$ students that dedicate time and efforts to scientific research, enriching the institutional efficiency in this regard.

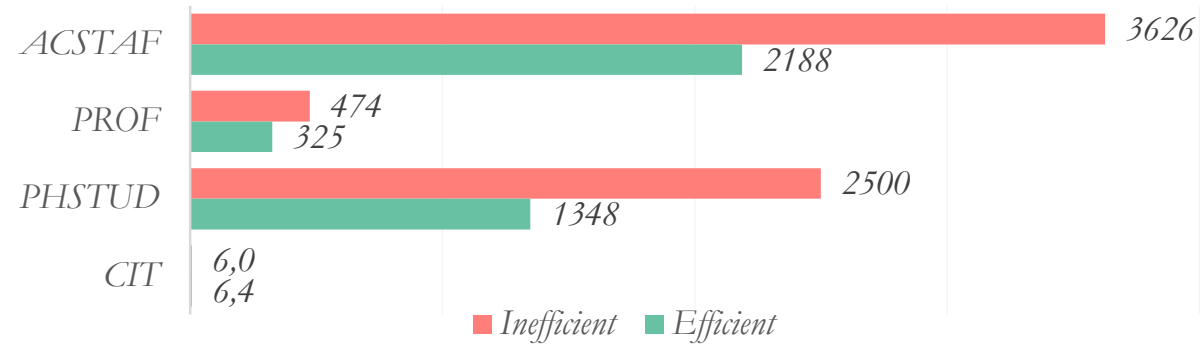

Figure 3. Comparison between efficient and inefficient universities, according to the research model 2 (higher publications)

In this case, things look slightly trickier. All universities are prestigious, well-known and offer a strong focus to research, being involved into various types of activities. Therefore, their emphasis is no longer set on improving their exposure and the number of publications, but on increasing the quality of their scientific work, quantified by citation score. As shown in Figure 3, inefficient universities have higher inputs, almost double in some cases, whilst the efficient group uses lower personnel but manages to deliver a slightly higher citation score. Although the differences in output are not large, the differences in the inputs used to produce that level of outcome are substantial, easily discriminating the efficient HEIs from the inefficient ones.

\subsection{Nonparametric efficiency analysis: Teaching}

The teaching aspect of the universities was treated in a similar manner to the research dimension. The number of publications is an indicator specific to research and therefore it could not be used in the teaching model, so filter previously applied had to be removed. Going back to the initial data containing all 264 universities, we still needed to ensure that a homogenous data set is provided for the non-parametric efficiency analysis. After excluding few common-sense outliers in terms of the teaching variables that would have bias the analysis, we employed a k-means cluster 
analysis and discovered two clusters: a group containing 51 large and prestigious but scattered universities and a second group with 208 small and medium-sized closer universities. Second cluster proved out to be homogenous and we decided to study the teaching efficiency on this group.

\section{Teaching model}

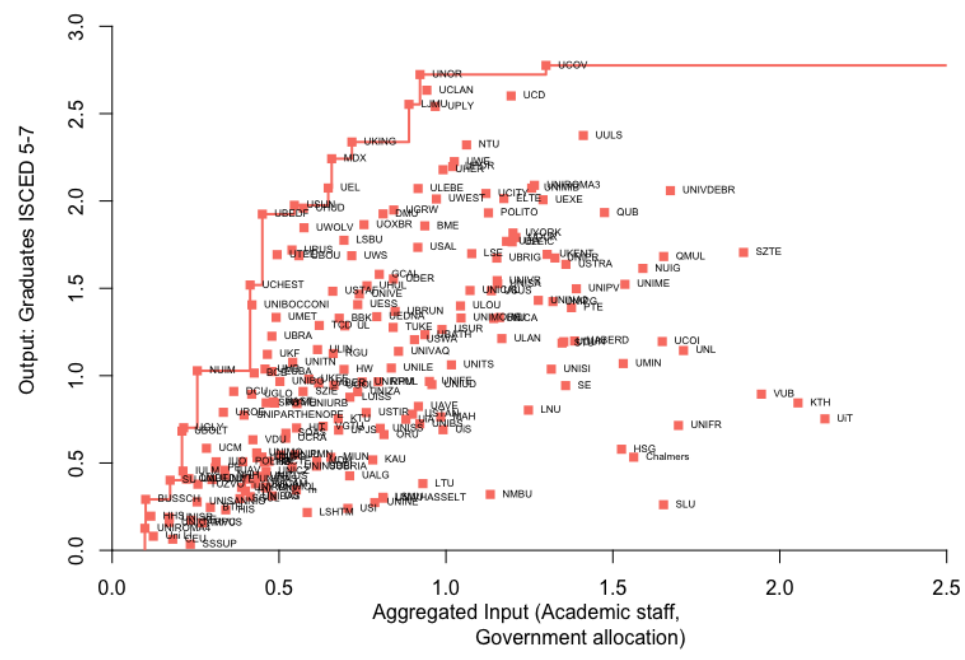

Figure 4. Efficiency frontier (FDH) for the teaching model.

Teaching efficiency is defined in this study by how well the institutions manage to use their government allocation and academic staff in producing the maximum amount of undergraduate degrees. The average FDH efficiency estimate for this model reaches 0.5152 , varying from 0.05 to 1 , related to which 113 universities $(54.3 \%$ of sample) are considered inefficient and 95 efficient ( $45.7 \%$ of sample).

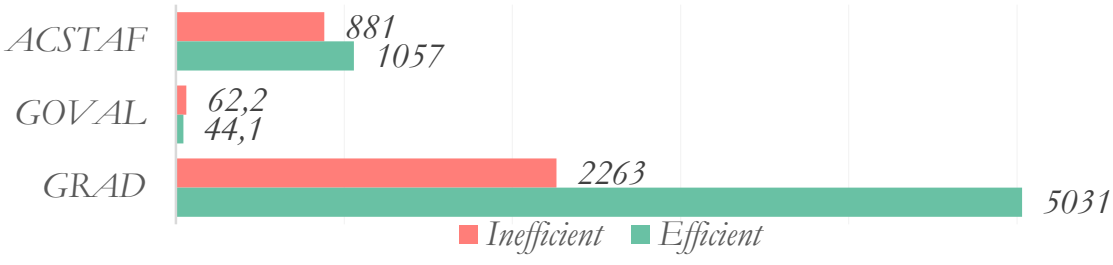

Figure 5. Comparison between efficient and inefficient universities, according to the teaching model

The results are illustrated in the chart above. HEIs with efficiency below mean have an average staff of 881 academics and use government 
allocation funds around 62.2 million euros in order to produce an average of 2263 ISCED 5-7 graduates. On the other hand, efficient universities have an average staff of 1057 academics and receive around 44.1 million euros of government funds, which they use to produce an average of 5031 graduates. In this configuration, there are a few examples of universities with good performance across both dimensions. London Business School offers such an example, achieving maximum estimate of efficiency for both teaching and research. With personnel of 105 academics and 45 full professors and government funds of around 9.4 million euros, this HEI produced 975 graduates and alongside its $75 \mathrm{PhD}$ students created no less than 35 publications and had 8 participations in EU-FP research programs. They boast with numerous teaching techniques, that seem to prove out quite efficient. The research is also well structured in various research centres and institutes, each of them focusing on a single business direction with the purpose to innovate business thinking and influence current and future business leaders and policy-makers.

Table 3. Rankings according to each model: country, number in the dataset.

\begin{tabular}{lll}
\hline Research model 1 & Research model 2 & Teaching model \\
\hline Italy, 82 & Switzerland, 15 & Italy, 82 \\
Ireland, 32 & Belgium, 3 & Ireland, 32 \\
Ireland, 30 & Ireland, 29 & UK, 209 \\
Lithuania, 105 & Italy, 73 & Lithuania, 105 \\
UK, 211 & Portugal, 120 & UK, 182 \\
Hungary, 18 & Sweden, 137 & UK, 190 \\
UK, 224 & Sweden, 135 & UK, 203 \\
UK, 267 & UK, 170 & UK, 211 \\
Italy, 90 & UK, 192 & UK, 219 \\
Sweden, 138 & Italy, 88 & UK, 221 \\
\hline
\end{tabular}

Last, but not the least, we produced the rankings of the universities, according to each model detailed above, by employing the hyperbolic measures of efficiency. This approach removes the orientation used in the previously models and explores any possible combinations by diminishing the input with $\gamma$, simultaneously with increasing the output with $\gamma^{-1}$. First ten universities from each top are provided in Table 3, all of them having a 
maximum hyperbolic efficiency estimate of 1. Interestingly, in their according FDH model, all of them were also having the maximum efficiency. Useful insights noticeable from the ranking are that only few of the universities efficient in the research model 1 (with lower publications) are also efficient in the teaching model. But this conclusion is not valid for the universities efficient in model 2 (higher amount of publications), who tend to concentrate on improving their citation rate and other research outputs, but lose some focus on the teaching aspects.

\section{Conclusions}

Higher Education Institutions have a fundamental mission on teaching and research, together with some other institutional missions that need to be delivered through their activity. With these responsibilities, universities often struggle to optimally use their available resources in pursuance of both educational and research outputs, while competing for gathering funds and finding a balance between those aspects.

The aim of this paper was to examining two dimensions of European universities (teaching and research), alongside a possible ranking based on the models we employed for each perspective. We performed some data cleaning and dimension reduction techniques and we used nonparametric efficiency analysis using Full Disposal Hull and Hyperbolic efficiency estimators based on the data provided by RISIS-ETER facility.

Efficiency in research is attained by concentrating the academic efforts in publishing and participating to various European research programs, no matter the academic personnel. On the other hand, efficiency in teaching requires some focus on producing as much ISCED 5-7 graduates as possible. The findings prove that only few universities achieve efficiency in both teaching and research. Most institutions are focusing all their efforts into a single direction and the other one suffers consequently.

A follow-up on this study involves several other approaches. We intend to employ some order-m or order-alpha frontiers to the dataset in order to identify some super-efficient universities located below the production frontier. A comparison between 2014 and a most recent year could highlight how the ranking evolved and what drives the universities to switch from inefficient to efficient or vice versa. Another interesting aspect worth studying is adding some teaching quality indicators and analyse this dimension separately, although the data is very scarce in this regard. 


\section{References}

[1] Abbot M, Doucouliagos C. The efficiency of Australian universities: a data envelopment analysis. Economics of Education. 2003;22(1):89-97.

[2] Bonaccorsi A, Daraio C, Simar L. Advanced indicators of productivity of universities. An application of robust nonparametric methods to Italian data. Scientometrics. 2006;66(2):389-410.

[3] Curi C, Daraio C, Llerena P. University Technology Transfer: How (in)efficient are French universities? Cambridge Journal of Economics. 2012;36(3):629-654.

[4] Daraio C, Bonaccorsi A, Simar L. Rankings and university performance: A conditional multidimensional approach. European Journal of Operational Research. 2015;244(3):918-930.

[5] Daraio C, Bonaccorsi A, Simar L. Efficiency and economies of scale and specialization in European universities: A directional distance approach. Journal of Informetrics. 2015;9(3):430-488.

[6] Daraio C, Simar L. Advanced robust and nonparametric methods in efficiency analysis: Methodology and applications. Springer Science \& Business Media; 2007.

[7] Deprins D, Simar L, Tulkens H. (1984). Measuring labor efficiency in post offices. In: Marchand M, Pestieau P, and Tulkens H, editors. The Performance of Public Enterprises: Concepts and Measurements. Amsterdam, NorthHolland, 243-267, 1984.

[8] Färe R, Grosskopf S. A nonparametric cost approach to scale efficiency. The Scandinavian Journal of Economics. 1985;594-604.

[9] Mouchart M, Simar L. Efficiency Analysis of Air Controllers: First Insights. Consulting report no. 0202, Institut de Statistique, UCL, Belgium; 2002.

[10] Simar L, Wilson PW. Statistical inference in nonparametric frontier models: The state of the art. Journal of productivity analysis. 2000;13(1):49-78.

[11] Stoica M, Aldea A. Efficiency of teaching and research activities in Romanian universities: An order-alpha partial frontiers approach. Economic Computation and Economic Cybernetics Studies and Research. 2016;50(4):169-186.

[12] Wilson PW. Asymptotic Properties of Some Non-Parametric Hyperbolic Efficiency Estimators. In: Van Keilegom I, Wilson P, eds. Exploring Research Frontiers in Contemporary Statistics and Econometrics. Physica, Heidelberg; 2011. p. 115-150. 